www.jmscr.igmpublication.org

Impact Factor (SJIF): 6.379

Index Copernicus Value: 71.58

ISSN (e)-2347-176x ISSN (p) 2455-0450

crossrefDOI: https://dx.doi.org/10.18535/jmscr/v6i6.190

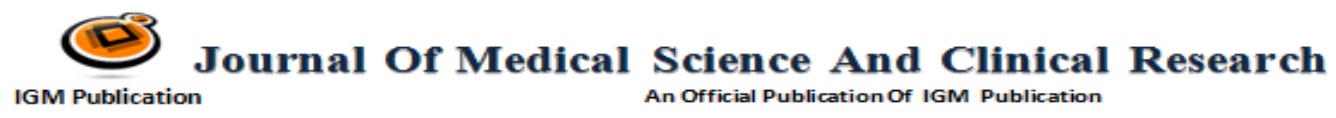

\title{
Fibro-osseous Lesions of Cranio-facial region: An Institutional Study
}

Authors

\section{Singh Rakesh Kumar ${ }^{1}$, Sinha Richi ${ }^{2}$, Mishra Sarita Kumari ${ }^{3}$}

Department of Otorhinolaryngology, Indira Gandhi Institute of Medical Sciences, Patna, India

*Corresponding Author

Singh Rakesh Kumar

Professor and Head, Department of Otorhinolaryngology, Indira Gandhi Institute of Medical Sciences,

Sheikhpura, Patna, India, Zip code: 800014

Email: rksent5@gmail.com, Mobile: +91 7781912005

\begin{abstract}
Introduction: Fibro-osseous lesions are a diverse group of bone disorders with fibrous dysplasia and ossifying fibroma as the major entities. They are extremely slow growing tumors that share overlapping clinical, radiographic and histopathologic features and demonstrate a wide range of biological behaviour.
\end{abstract}

Aim: To evaluate the clinical characteristics and management of patients with fibro-osseous lesions of the cranio-facial region.

Patients and Method: All the patients presenting with the fibro-osseous lesions of the head and neck region in the department of Otorhinolaryngology of Indira Gandhi Institute of Medical Sciences from 2012 to 2015 were included in this study.

Results: A total of 10 patients were diagnosed with fibro-osseous lesions of cranio-facial region. Fibrous dysplasia was seen in 6 cases and ossifying fibroma in 4.2 of the cases had extensive craniofacial involvement including maxilla, skull base with intracranial expansion. There was involvement of sphenoid in 3 cases, 4 cases involved maxilla and 7 cases had mandibular or the temporo-mandibular joint involvement. The most common presentation was a progressive painless swelling over face with facial asymmetry. All cases were managed surgically with complete or limited resection depending on the extent of disease and vigilant followup thereafter for any recurrence.

Conclusions: Fibro-osseous lesions are a group of slow growing benign tumors with overlapping clinical, radiological and microscopic features. However their disease course is so variable that the treatment needs to be individualized. Extensive treatment is preferred to prevent recurrence, we suggest a more conservative approach of maximum resection with minimum morbidity to be the goal of surgery for huge lesions.

Keywords: Maxillofacial, ossifying fibroma,fibrous dysplasia, mandible, cemento-ossifying.

\section{Introduction}

Fibro-osseous lesions is a diverse group of benign bone disorders of the anterior skull base and facial skeleton. Histologically, it is characterized by re- placement of normal bone with connective tissue matrix of varying degree of mineralization. Based on this, it is classified into mainly fibrous dysplasia, ossifying fibroma and other less common var- 
iants $^{[1,2]}$. Clinically these lesions are mostly asymptomatic and present with slowly progressive swelling and facial asymmetry. Ossifying fibromas are differentiated radiologically from fibrous dysplasia by a bony capsule. Treatment of choice is surgical resection and is necessary only when functional problems arise or cosmetic deformity occurs. The purpose of this study is to analyze the clinical characteristics and management of fibroosseous lesions reported at our centre.

\section{Patients and Method}

A total of 10 patients histologically diagnosed with the fibro-osseous lesions of the head and neck region in the department of Otorhinolaryngology of Indira Gandhi Institute of Medical Sciences from 2012 to 2015 were included in this study. A note of detailed history and thorough clinical examination was made. Computed tomography evaluation of all the patients was done. Surgical resection of the lesion was performed in all 10 cases with a minimum followup period of 1 year.

\section{Results}

During the 3 years of study period a total of 76 cases of cranio-facial swelling were encounterd. Out of these, 10 cases were found histologically confirmed as fibro-osseous lesion. Fibrous dysplasia was seen in 6 cases and ossifying fibroma in 4 cases with male preponderance in all of them. 2 of the cases had extensive craniofacial involvement including maxilla, skull base with intracranial expansion. There was involvement of ethmoid in 4 cases, sphenoid in 3 cases, 4 cases involved maxilla and 7 cases had mandibular or temporomandibular joint involvement. The most common presentation was a progressive painless swelling over face with facial asymmetry. All cases were managed surgically with complete or limited resection depending on the extent of disease and vigilant followup thereafter for any recurrence. table 1-4 summarizes the clinical parameters of this study.

\begin{tabular}{|l|c|c|c|}
\hline Gender & $\begin{array}{c}\text { fibrous } \\
\text { dysplasia }\end{array}$ & $\begin{array}{c}\text { ossifying } \\
\text { fibroma }\end{array}$ & total \\
\hline male & 4 & 4 & 8 \\
\hline female & 2 & 0 & 2 \\
\hline
\end{tabular}

\begin{tabular}{|l|c|c|c|}
\hline Age range & $\begin{array}{c}\text { fibrous } \\
\text { dysplasia }\end{array}$ & $\begin{array}{c}\text { ossifying } \\
\text { fibroma }\end{array}$ & total \\
\hline $\mathbf{0 - 2 0}$ & 4 & 3 & 7 \\
\hline $\mathbf{2 1 - 4 0}$ & 2 & 1 & 3 \\
\hline $\mathbf{4 1 - 6 0}$ & 0 & 0 & 0 \\
\hline above 60 & 0 & 0 & 0 \\
\hline
\end{tabular}

\begin{tabular}{|l|c|c|c|}
\hline site & $\begin{array}{c}\text { fibrous } \\
\text { dysplasia }\end{array}$ & $\begin{array}{c}\text { ossifying } \\
\text { fibroma }\end{array}$ & total \\
\hline maxilla & 1 & 3 & 4 \\
\hline mandible & 5 & 2 & 4 \\
\hline temporal & 1 & 0 & 1 \\
\hline frontal & 1 & 1 & 2 \\
\hline sphenoid & 2 & 1 & 3 \\
\hline ethmoid & 1 & 3 & 4 \\
\hline
\end{tabular}

\begin{tabular}{|l|c|c|}
\hline Treatment & $\begin{array}{c}\text { fibrous } \\
\text { dysplasia }\end{array}$ & $\begin{array}{c}\text { ossifying } \\
\text { fibroma }\end{array}$ \\
\hline cyst excision & 0 & 2 \\
\hline curettage & 0 & 2 \\
\hline debulking & 1 & 0 \\
\hline partial maxillectomy & 1 & 1 \\
\hline partial mandibulectomy & 2 & 1 \\
\hline complete resection & 5 & 2 \\
\hline
\end{tabular}

\section{Discussion}

Fibro-osseous lesions is a diverse group of benign bone disorders with overlapping clinical, radiographic and microscopic features making their specific diagnosis difficult. The disease process involves replacement of normal architecture of bone by fibrous tissue containing varying amount of foci of mineralization. Although mostly idiopathic, some are believed to be neoplastic or metabolic in origin ${ }^{[3]}$. Based on this various classifications of this group have been proposed till date ${ }^{[4-}$ ${ }^{5]}$. Broadly, these can be divided into two main categories; namely fibrous dysplasia and ossifying fibroma. Fibrous dysplasia may occur in monostotic (involving one bone) or polyostotic (multiple bones) forms. The former is more common. In our study also we found fibrous dysplasia to be more common FOL with mandible to be the commonest site of involvement. Table 5 summarizes the clinical parameter of our study with previous studies. 


\begin{tabular}{|l|c|c|c|}
\hline parameters & $\begin{array}{c}\text { our } \\
\text { study }\end{array}$ & $\begin{array}{c}\text { Ogunsalu } \\
\text { et al[6] }\end{array}$ & $\begin{array}{c}\text { Langdon } \\
\text { et al[7] }\end{array}$ \\
\hline $\begin{array}{l}\text { - Fibrous } \\
\text { dysplasia(FD) } \\
\text { - Ossifying } \\
\text { fibroma(OF) }\end{array}$ & 6 & 10 & 19 \\
\hline Age(FD) & 4 & 17 & 15 \\
Age(OF) & 28 & 25 & 24 \\
\hline M:F(FD) & 16 & 26 & 35 \\
M:F(OF) & $2: 1$ & $2: 3$ & $1: 1.5$ \\
\hline Mandible(FD) & M & $2: 3$ & $1: 1.23$ \\
Mandible(OF) & $50 \%$ & $40 \%$ & $80 \%$ \\
\hline Maxilla(FD) & $20 \%$ & $50 \%$ & $70 \%$ \\
Maxilla(OF) & $10 \%$ & $60 \%$ & $20 \%$ \\
\hline
\end{tabular}

Being slow growing tumors, most of the cases remain asymptomatic. Functional derrangement occurs when the lesions become huge or are situated near critical structures like orbit and temporomandibular joint leading to deviation of eye ball, diplopia, blurring of vision, trismus, etc. These lesions cause cosmetic and psychological problems ${ }^{[8]}$ as seen in 2 of our cases to an extent of suicidal tendency.

Though both the type of lesions have mostly common clinical, radiographic and microscopic features, they differ in their natural course. Ossifying fibromas tend to recur and hence require complete surgical removal. On the contrary, fibrous dysplasia has a tendency to stabilize with skeletal maturity. Reed viewed fibrous dysplasia as an arrest of bone maturation at the woven stage of development, whereas in ossifying fibroma normal bone architecture was replaced by a tissue composed of collagen fibers, fibroblasts, and various amounts of calcified tissue with the potential for unlimited and destructive growth ${ }^{[9]}$.

Radiographically, they may appear as radiolucent, mixed radiolucent/ radiopaque or as radiopaque lesion. Fibrous dysplasia are usually ill-defined blending imperceptibly into the surrounding bone. There may or may not be expansion of bone. On the other hand, ossifying fibroma appear as well defined spherical uni or multilocular expansile bony lesions ${ }^{[10]}$.

Histologically, both fibrous dysplasia and ossifying fibroma share common characteristics and markers consistent with the osteogenic lineage in their stromal fibroblast-like cells. However, there is abundance osteocalcin in former and hence can be distinguished by osteocalcin immunohistochemistry ${ }^{[11]}$.

Since fibrous dysplasia tend to stabilize with skeletal maturity, the surgical management should be delayed until then and the monitoring for rapid disease progression by serial radiographs at regular intervals should be done ${ }^{[12]}$. Treatment is indicated in symptomatic cases and involves limited resection to achieve functional integrity ${ }^{[11]}$. In contrat, ossifying fibromas being a well defined tumor, surgical removal and curettage is an effective treatment option ${ }^{[14,15]}$.

\section{Conclusion:}

Fibro-osseous lesions are a group of slow growing benign tumors with overlapping clinical, radiological and microscopic features. However their disease course is so variable that the treatment needs to be individualized. Extensive treatment is preferred to prevent recurrence, we suggest a more conservative approach of maximum resection with minimum morbidity to be the goal of surgery for huge lesions.

\section{References}

1. Abdulai AE, Gyasi RK. Iddarissu MI. Benign Fibroosseous lesions of the facial skeleton: Analysis of 52 cases seen at the Korle $\mathrm{Bu}$ teaching hospital. Ghana Med J 2004;38(3):96-100

2. Ram R, Singhal A, Singhal P. (2012). Cemento-ossifying fibroma. Contemp Clin Dent, 3, 83-5

3. Bahl R, Sandhu S, Gupta M. Benign fibroosseous lesions of jaws - A Review. Int Dent J Stude Res. 2012;1(2):56-68

4. Rajpal K, Agarwal R, Chhabra R, Bhattacharya M. Updated Classification Schemes for Fibro-Osseous Lesions of the Oral \& Maxillofacial Region: A Review. IOSR Journal of Dental and Medical Sciences. 2014;13(2):99-103. 
5. Tawab HMA, Raafat SA, Naseem NT, Megahed AS. Retrospective study for diagnosis and management of fibro-osseous lesions affecting para nasal sinuses.PAN Arab Journal of Rhinology, 2013;3(1):917.

6. Ogunsalu CO, Lewis A, Doonquah L, authors. Benign fibro-osseous lesions of the jaw bones in Jamaica: Analysis of 32 cases. Oral Dis. 2001;7:155-62.

7. Langdon JD, Rapidis AD, Patel MF, authors. Ossifying Fibroma-one disease or six? An analysis of 39 fibro-osseous lesions of the jaws. $\mathrm{Br} \mathrm{J}$ Oral Surg. 1976;14:1-11.

8. Vankeviciute RA, Neverauskiene A, Lukosevicius E. Fibro-osseous lesions of craniofacial bones in children: case reports. Acta Medica Litu. 2013;20(2):93-101.

9. ReedRJ.Fibrousdysplasiaofbone.Archiveso fPathology1963;75:480-495.

10. Suarez-Soto A, Baquero-Ruiz de la Hermosa MC, Minguez-Martínez I, FloríaGarcía LM, Barea-Gámiz J, DelhomValero J, Risueño-Mata P. Management of fibro-osseous lesions of the craniofacial area. Presenta- tion of 19 cases and review of the literature. Med Oral Patol Oral Cir Bucal. 2013 May 1;18 (3):e479-85

11. Toyosawa S, Yuki M, Kishino M, Ogawa Y, Ueda T, Murakami S, Konishi E, Iida S, Kogo M, Komori T, Tomita Y. Ossifying fibroma vs fibrous dysplasia of the jaw: molecular and immunological characterization. Mod Pathol. 2007;20:389-96.

12. Lee J, Fitzgibbon E, Chen Y et al Clinical guidelines for the management of craniofacial fibrous dysplasia. Orphanet J Rare Dis 2012;7(Suppl 1):S2.
13. Cholakova R, Kanasirska P, Kanasirski N, Chenchev Iv, Dinkova A. Fibrous dysplasia in the maxillomandibular region - Case report. J IMAB - Annu Proc (Scientific Papers) 2010;16(book 4)

14. Sinha R, Singh RK, Devi S, Kumar S, Singh A, Kumar R. JUVENILE AGGRESSIVE CEMENTO-OSSIFYING FIBROMA OF MANDIBLE: A RARE CASE REPORT. International Journal Of Advances In Case Reports, 2015;2(15):952-954.

15. M de Andrade, YTC Silva-Sousa, MFT Marques, et al. Ossifying Fibroma of the Jaws: A Clinicopathological Case Series Study. Brazilian Dental Journal. 2013;24:662-66. 